\title{
Treatment of Carotid Stenosis in Octogenarians: Stenting or Surgery?
}

Can. J. Neurol. Sci. 2011; 38: 385-386

Incidence of symptomatic carotid stenosis rises steeply with age, and an increasing population life expectancy makes treatment decisions in the elderly more relevant today than when the landmark carotid endarterectomy (CEA) trials were conducted. With an approximate $37 \%$ stroke risk at two years ${ }^{1}$, the question is not whether to treat severe symptomatic stenosis in the elderly, but more appropriately whether to stent or operate. Carotid angioplasty and stenting (CAS) has evolved into a popular alternative to carotid endarterectomy for the treatment of carotid stenosis, particularly after publication of the largest randomized controlled trial (RCT) comparing the two procedures [Carotid Revascularization Endarterectomy versus Stent Trial (CREST) $]^{2}$. Octogenarians however were excluded from this trial due to evidence suggesting that they are at increased risk with CAS. In this issue of the journal, Calgary investigators report on their experience with CAS in octogenarians ${ }^{3}$ and they clearly wish to change this perception.

\section{Carotid Artery Stenting in the Elderly}

The CAS literature is replete with single centre case series and retrospective reviews. There are registries and industry supported studies with investigators from multiple disciplines looking at often-heterogeneous populations of symptomatic and asymptomatic patients. A common theme in many of the reports has been the dangers of this procedure in very elderly patients. The risk of major adverse effects, particularly stroke, death and myocardial infarction ranges from $2.1-25 \%^{4-8}$. A review of 11 studies totaling 933 octogenarians showed an overall stroke risk of $9 \%$ in this group. Elderly patients were particularly prone to significant hemodynamic depression following balloon angioplasty ${ }^{4}$. One of the largest CAS registries of almost 3,000 patients includes 322 octogenarians ${ }^{9}$. Compared to younger patients, their procedures were longer, more often associated with peri-procedural adverse events, and more likely to be aborted due to unfavourable anatomy. They had twice the risk of in-hospital stroke, death or transient ischemic attack. The authors believe that pooled registry data "clearly show increasing age to be an independent predictor of in-hospital death and stroke rates".

Information from RCTs of CAS vs. CEA has shown similar results. The association between advanced age and increased risk with CAS was seen in the Stent-Protected Angioplasty versus Carotid Endarterectomy (SPACE) trial, the International Carotid Stenting Study (ICSS) and the lead-in phase to CREST ${ }^{10-12}$. As patient selection, operator experience and technology improve, it has been shown that CAS can be done safely in octogenarian ${ }^{13}$, yet even interventionalists as experienced as the Calgary group report a $10.2 \%$ cumulative risk of stroke or death at 30 days.

\section{Should CAS be used as first-line treatment?}

Unlike CAS, where perioperative risk increases with increasing age, perioperative stroke and death remains reasonably consistent across all age groups for $\mathrm{CEA}^{14-17}$. Subgroup analysis from North American Symptomatic Carotid Endarterectomy Trial (NASCET) suggests that the benefit from surgery was greatest amongst patients aged 75 and over, with a $\mathrm{NNT}=3$ for severe symptomatic stenosis ${ }^{1}$. Perioperative stroke and death for CEA in patients $>=75$ years in NASCET was $5.2 \%$, in comparison to the $12.1 \%$ for similarly aged CAS patients in CREST. Given the consistent safety advantage of CEA over CAS in the elderly, it would be wise to consider CEA as first-line therapy for symptomatic carotid stenosis in the elderly. High risk features for CEA (significant cardiac or pulmonary disease, history of radiation, presence of contralateral stenosis, high cervical lesions, or previous CEA), would provide reason to consider CAS. Risk analysis by Rothwell ${ }^{18}$ suggests that even with best medical management, the stroke risk remains high in the elderly, and a treatment with up to $10 \%$ risk of perioperative stroke and death still provides a prophylactic benefit. The Calgary group notes that their perioperative mortality occurred early in their experience, and was absent in the more contemporary cohort. Improvement in their perioperative stroke and death rate is likely a composite of increasing technical skills, and patient selection.

\section{Imaging Assists Patient Selection}

The ready availability of high quality CT-angiograms (CTA) and MRI/MRA not only allows for the identification of carotid stenosis in the symptomatic individual, but also factors highly in assessing the suitability for CEA or CAS. Either of these modalities allows for accurate assessment of stenosis, location of bifurcation, length of plaque, and intracranial collateral circulation. Most importantly for CAS, both modalities provide anatomical information about the aortic arch, common carotid artery, and the distal cervical internal carotid artery. For plaque specific features, CTA better predicts the degree of calcification, whereas MRI can detect potentially unstable intra-plaque hemorrhage. Difficult endovascular access, looping distal cervical internal carotid arteries, and highly calcified plaque have been proposed to increase the risk of perioperative complications following CAS.

The article by Almekhlafi et $\mathrm{al}^{3}$ demonstrates that an experienced endovascular group can effectively provide CAS for stroke prophylaxis in the octogenarian population. We caution however, that CEA should be considered first, and if CAS is deemed to be more appropriate, then the treating physician should have a perioperative stroke and death rate approximating no more than $10 \%$. Any future studies of CAS must prospectively account for age given the strong effect on perioperative risk. 


\section{REFERENCES}

1. Alamowitch S, Eliasziw M, Algra A, Meldrum H, Barnett HJM, for the North American Symptomatic Carotid Endarterectomy Trial (NASCET) Group. Risk, causes, and prevention of ischaemic stroke in elderly patients with symptomatic internal-carotidartery stenosis. Lancet. 2001;357:1154-60.

2. Brott TG, Hobson RW II, Howard G, et al. Stenting versus endarterectomy for treatment of carotid artery stenosis. N Engl J Med. 2010;363:11-23.

3. Almekhlafi MA, Couillard PL, Pandya A, et al. Outcomes after carotid angioplasty and stenting in symptomatic octogenarians. Can J Neurol Sci. 2011;38(3):446-51.

4. Linfante I, Andreone V, Akkawi N, Wakhloo AK. Internal carotid artery stenting in patients over 80 years of age: single-centre experience and review of the literature. J Neuroimaging. 2009; 19:158-63.

5. Grant A, White C, Ansel G, Bacharach M, Metzger C, Velez C. Safety and efficacy of carotid stenting in the very elderly. Catheter Cardiovasc Interv. 2010;75:651-5.

6. Stanziale SF, Marone LK, Boules TN, et al. Carotid artery stenting in octogenarians is associated with increased adverse outcomes. J Vasc Surg. 2006;43:297-304.

7. Roubin GS, New G, Iyer SS, et al. Immediate and late clinical outcomes of carotid stenting in patients with symptomatic and asymptomatic carotid artery stenosis. Circulation. 2001;103: $532-7$

8. Mathur A, Roubin GS, Iyer SS, et al. Predictors of stroke complicating carotid artery stenting. Circulation. 1998;97: 1239-45.

9. Zahn R, Ischinger T, Hochadel M, et al. Carotid artery stenting in octogenarians: results from the ALKK Carotid Artery Stent (CAS) Registry. Eur Heart J. 2007;28:370-5.
10. Ringleb PA, Allenberg J, Bruckman $\mathrm{H}$, et al. 30 day results from the SPACE trial of stent- protected angioplasty versus carotid endarterectomy in symptomatic patients: a randomized noninferiority trial. Lancet. 2006;368:1239-47.

11. Ederle J, Dobson J, Featherstone RL, et al. Carotid artery stenting compared with endarterectomy in patients with symptomatic carotid stenosis (International Carotid Stenting Study): an interim analysis of a randomized controlled trial. Lancet. 2010; 375:985-97.

12. Hopkins LN, Roubin GS, Chakhtoura EY, et al. The Carotid Revascularization Endarterectomy versus Stenting Trial: credentialing of interventionalists and final results of lead-in phase. J Stroke Cerebrovasc Dis. 2010;19:153-62.

13. Chaim PT, Roubin GS, Iyer SS, et al. Carotid artery stenting in elderly patients: importance of case selection. Catheter Cardiovasc Interv. 2008;72:318-24.

14. Lichtman JH, Jones SB, Wang Y, et al. Postendarterectomy mortality in octogenarians and nonagenarians in the USA from 1993 to 1999. Cerebrovasc Dis. 2010;29(2):154-61.

15. Vogel TR, Dombrovskiy VY, Haser PB, Scheirer JC, Graham AM. Outcomes of carotid artery stenting and endarterectomy in the United States. J Vasc Surg. 2009;49(2):325-30; discussion 330.

16. Ballotta E. Da Giau G. Ermani M, et al. Early and long-term outcomes of carotid endarterectomy in the very elderly: an 18year single-center study. J Vasc Surg. 2009;50(3):518-25.

17. Bremner AK. Katz SG. Are octogenarians at high risk for carotid endarterectomy? J Am Coll Surg. 2008;207(4):549-53.

18. Rothwell P. Carotid endarterectomy and prevention of stroke in the very elderly. Lancet. 2001;357(9263):1142-3. 